ISSN 0103-9954

\title{
DETERMINAÇÃO DO PONTO DE AMOSTRAGEM PARA A OBTENÇÃO DA CONCENTRAÇÃO MÉDIA DE TANINO EM ACÁCIA ${ }^{1}$
}

\section{DETERMINATION OF SAMPLING POINT FOR THE MEASUREMENT OF THE AVERAGE CONCENTRATION OF TANNIN IN ACACIA}

\author{
Shirlei B. de Aguiar Camillo ${ }^{2}$ Paulo Renato Schneider ${ }^{3}$ \\ Maria Cladis M. da Silva ${ }^{4}$ Sonia Maria Bitencourt Frizzo ${ }^{4}$
}

\section{RESUMO}

A altura de amostragem, nas árvores de acácia onde obtém-se a concentração média de tanino, foi estudado em população de acácia-negra, Acacia mearnsii de Willd. Considerando-se a concentração de tanino (CTA) em função da relação altura de amostragem (hi) sobre a altura total (h), obteve-se a seguinte equação: hi/h $=1,122747$ - 0,046494 • CTA. Substituindo-se CTA na equação, pelo valor médio da concentração de tanino encontrado de $15,52165 \%$, chegou-se ao valor $\mathrm{hi} / \mathrm{h}=0,401083$. Isto permitiu concluir que a concentração média de tanino pode ser determinada num único ponto de amostragem, localizado a $40 \%$ da altura total das árvores, independente da idade.

Palavras-chave: Acacoa mearnsii, tanino, altura de corte.

\begin{abstract}
The height of the sampling point in acacia trees, where the medium tannin concentration is located, was studied for black acacia, Acacia mearnsii De Willd. The equation hi/h=1.22747 0.046494.CTA was obtained relating the sample height over the total height to the tannin concentration. Substituing the medium value of CTA, $15.52165 \%$, the value 0.401983 is obtained

1. Parte da Dissertação de Mestrado apresentada pelo primeiro autor ao Programa de PósGraduação em Engenharia Florestal da Universidade Federal de Santa Maria (UFSM) para obtenção do Grau de Mestre em Engenharia Florestal.

2. M.Sc., Prof ${ }^{a}$. do Departamento de Química/CCNE/UFSM. CEP: 97105-900. Santa Maria. RS.

3. Eng. Florestal, Dr., Prof. do Departamento de Ciências Florestais/CCR/UFSM. CEP: 97105-900. Santa Maria. RS.

4. Enga . Florestal, M.Sc., Prof ${ }^{a}$. do Departamento de Química/CCNE/UFSM. CEP: 97105-900. Santa Maria. RS.
\end{abstract}


for hi/h. We concluded that the medium concentration of tannin can be determined at a single height, $40 \%$ of the total of the tree stem, independent of the age of the tree.

Key words: Acacia mearnsii, tannin, cut height.

\section{INTRODUÇÃO}

O valor econômico das florestas de acácia-negra é determinado pela madeira, a qual é utilizada na fábrica de celulose, e principalmente pelo tanino, presente na casca das árvores (TANAC, 19--). Pertencentes a um grupo de substâncias denominadas de "glicosídios polifenólicos", os taninos vegetais representam um grupo de substâncias de composição química muito variável e de estrutura complexa, com peso molecular entre 500 a 3.000 u. Presentes nos tecidos de diversos vegetais, apresentam como principais características a solubilidade em água e a capacidade de ligarse com proteínas e/ou precipitar proteínas solúveis em água (REICHER et al., 1981). É um extrato vegetal que pode atender as mais variadas aplicações, uma delas a transformação da pele de animais em couro (OLIVEIRA, 1968). A concentração de taninos, segundo PEREIRA et al., 1985 e SCHÖNAU, 1969, cresce da base para o topo das árvores. Este tipo de distribuição dificulta a determinação do conteúdo médio de taninos por árvores, porque são necessários múltiplas amostragens ao longo do tronco.

Este trabalho colabora no sentido de minimizar este fato, ou seja, conhecendo-se a altura do ponto representativo de amostragem na árvore, reduz-se a quantidade de trabalho para a estimativa da quantidade de tanino por árvore.

\section{MATERIAL E MÉTODOS}

Estudou-se quatorze unidades amostrais, constituídas por povoamentos de acácia-negra com idade variando dos três aos oito anos. De cada uma das quatorze unidades amostrais, selecionou-se duas árvores, uma de maior diâmetro e uma de diâmetro médio, ao nível do DAP. Os povoamentos de acácia localizam-se na Depressão Central e Encosta Inferior do Nordeste do estado do Rio Grande do Sul e pertencem a empresa Tanac S.A. O clima dessa região do Rio Grande do Sul é classificado como mesotérmico brando, super úmido, sem seca, ou sub-tropical. O inverno é bastante sensível, possuindo pelo menos um mês com temperatura média máxima de $15^{\circ} \mathrm{C}$ e média mínima de $13^{\circ} \mathrm{C}$. No verão apresenta uma média máxima superior a $30^{\circ} \mathrm{C}$, chegando em janeiro a ser superior a $32^{\circ} \mathrm{C}$. As geadas são freqüentes nos meses mais frios, ocorrendo numa média de 10 dias ao ano. Nesta região não ocorre déficit hídrico, com chuvas uniformemente distribuídas durante o ano (IBGE, 1990). A geologia dessa região é representada por sedimentos permotriássicos da Bacia do Paraná, sendo que o arenito triássico ocupa a maior parte. Desta forma predominam os solos arenosos e saibrosos com pequeno teor e partes integrantes finos de sedimentos paleozóicos (BRASIL, 1971).

Estas árvores foram abatidas e retiraram-se discos de $10 \mathrm{~cm}$ de espessura nos pontos: base, 
DAP, $25 \%, 50 \%, 75 \%$ e $100 \%$ da altura total. Imediatamente após a coleta retirou-se a casca dos discos, a qual convenientemente identificada e levada para o laboratório.

No laboratório, as cascas foram secadas em estufa a $25^{\circ} \mathrm{C}$ até peso constante e após foram moídas e armazenadas em frascos com tampa. Para a extração do tanino utilizou-se duas gramas de casca moída, tomando-se cinco amostras em cada ponto.

A extração dos taninos processou-se em autoclave a $112^{\circ} \mathrm{C}$, o que corresponde a 0,6 atm de pressão, durante quatro horas, segundo SILVA \& FRIZZO (1985). Após obtido os extratos estes foram diluídos convenientemente e os taninos presentes foram quantificados por espectrofometria. $\mathrm{Na}$ aplicação do referido método utilizou-se o reativo de folinciocalteau (RFC), que consiste de uma mistura aquosa dos ácidos fosfomolibdico e fosfotúngstico (FOLIN \& CIOCALTEAU, 1927). Ocorre entre os taninos e o RFC uma reação de oxi-redução, onde este reagente é reduzido pelos taninos a seus respectivos óxidos, resultando no aparecimento de cor azul (KLOSTER, 1974).

Utilizando-se o espectrofotômetro Perkin Elmer, lâmbda 16 UV/Visível e comprimento de onda para a leitura de $755 \mathrm{~nm}$ obteve-se a concentração de tanino em g\% (CTA) em cada ponto de amostragem ao longo do fuste das árvores.

A análise estatística realizou-se com o uso da regressão, determinados através do pacote SAS (1993).

\section{RESULTADOS E DISCUSSÃO}

A altura de amostragem, onde obtém-se a concentração média de tanino no fuste das árvores foi estudado levando-se em consideração a concentração de tanino (CTA) em função da relação altura de amostragem (hi) sobre a altura total (h). A modelagem desta relação resultou numa equação de regressão que permite estimar a concentração de tanino, tendo sido obtida a função:

$$
\text { CTA }=17,679719-5,380689 \text {. (hi/h) }
$$

Esta equação apresentou um erro padrão de estimativa de CTA igual a 0,93 e um coeficiente de correlação igual a 0,5 .

Para viabilizar a determinação do ponto médio de amostragem determinou-se a mesma equação porém com inversão das variáveis dependente pela independente, resultando na equação:

$$
\mathrm{hi} / \mathrm{h}=1,122747-0,046494 . \mathrm{CTA}
$$

Para todas as árvores amostradas, com idade de três a oito anos, a concentração média de tanino foi de $15,52165 \%$, com um desvio padrão 2,21 , para um valor mínimo observado de $9,47 \%$ e o máximo de $18,76 \%$.

Substituindo-se o valor médio da concentração de tanino na equação acima (2), obtém-se o valor de 0,401083 . Isto significa que a determinação de tanino em uma árvore pode ser feita numa única altura de amostragem, tomado a $40 \%$ da altura total da árvore.

Graficamente o ponto médio da amostra pode ser observado através da Figura 1. 


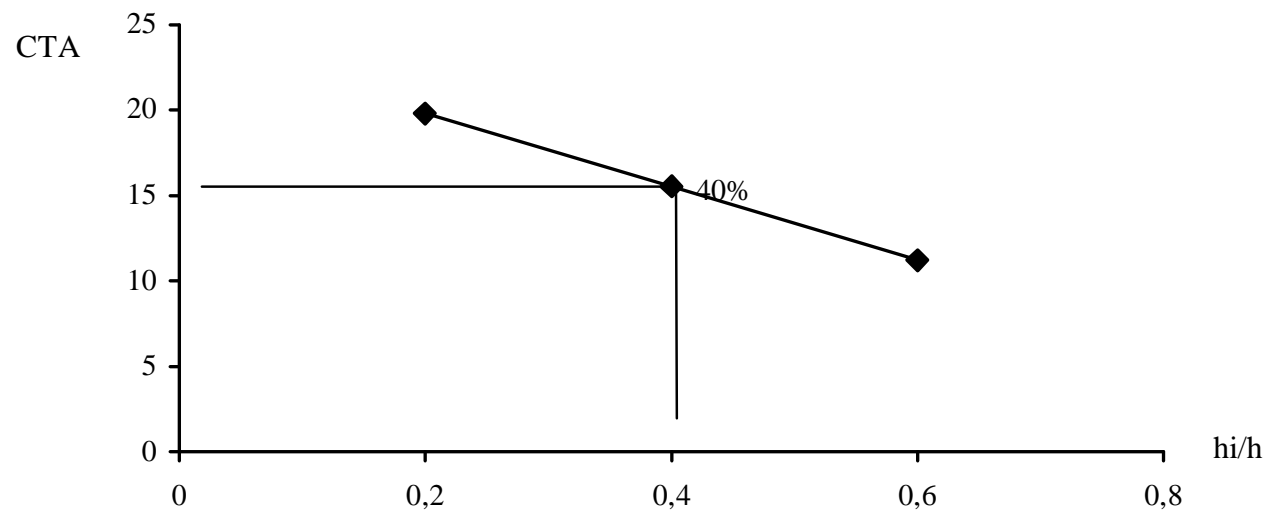

FIGURA 1: Ponto de amostragem para determinação da concentração média de taninos (CTA).

A determinação da altura relativa do fuste com a concentração média de tanino, por idade, pode ser observada na Tabela 1 .

TABELA 1: Altura relativa no fuste com a concentração média de tanino por idade.

\begin{tabular}{c|c|c}
\hline $\begin{array}{c}\text { Idade } \\
(\text { anos })\end{array}$ & $\begin{array}{c}\text { Tanino } \\
(\%)\end{array}$ & $\begin{array}{c}\text { Altura relativa do fuste com } \\
\text { concentração média de tanino }\end{array}$ \\
\hline 3 & 14,83 & 0,39 \\
4 & 15,47 & 0,41 \\
5 & 14,35 & 0,40 \\
6 & 15,72 & 0,40 \\
7 & 15,11 & 0,40 \\
8 & 17,09 & 0,41 \\
\hline Geral & 15,52 & 0,40 \\
\hline
\end{tabular}

Verifica-se uma variação muito pequena da altura relativa com a variação da idade, aproximadamente de $1 \%$, que pode ser explicado por algumas variações na forma do tronco das árvores e fatores do meio, como a qualidade do sítio. No entanto, esta pequena variação permite que se utilize altura relativa média tomada a $40 \%$ da altura total para determinar a concentração de tanino, independente da idade.

\section{CONCLUSÃO}

Pode-se determinar a concentração média de tanino presente por árvore em povoamentos de acácia-negra, tomando-se uma única altura de amostragem a 40\% da altura total da árvore, sendo 
que esta altura independe da idade da árvore.

\section{REFERÊNCIAS BIBLIOGRÁFICAS}

BRASIL. Instituto Brasileiro de Desenvolvimento Florestal. Zoneamento econômico florestal do estado do Rio Grande do Sul. Curitiba, 1971, 125p.

FOLIN, O. \& CIOCALTEAU, V. On tyrosine on triptophane determinations in proteins. J. Biol. Chem., v. 73, n. 2, p. 627-651. 1927.

IBGE. Geografia do Brasil. Rio de Janeiro, 1990. v.2. p.

KLOSTER, M. B. The determination of tanino and lignin. J. Amer. Water Works Ass., v. 66, n. 1, p. 44-46, 1974.

OLIVEIRA, H. A acácia-negra e tanino no Rio Grande do Sul. Canoas: La Salle, 1968. v.2, 12p.

PEREIRA, J. C. D., MAETRI, R., LAVORATI, O. K. O efeito do anelamento basal na produção de tanino em acácia-negra. Curitiba: EMBRAPA - Centro Nacional de Florestas, 1985. 3p.

REICHER, F., SIERAKOWSKI, M. R., CORRÊA, J. B. C. Determinação espectofotométrica de taninos pelo reativo fosfotungstico-fosfomolibdico. Arq. Biol. Tecnol., v. 24, n. 4, p. 407-411, 1981.

SAS INSTITUTE, SAS/STAT User's Guide: STATISTICS, 4, Version 6, Cary, NC: 1993, v.2.

SCHÖNAU, A. P. G. A site evaluation study in black wattle (Acacia mearnsii De Willd.). Ann. von Stellenbosch, v. 44, n. 2A, p. 214, 1969.

SILVA, M. C. \& FRIZZO, S. M. Determinação de tanino na casca da Acacia mearnsii De Wild. em diferentes alturas do tronco. Ciência e Natura. n. 7, p. 57-61, 1985.

TANAC Acácia-negra. Montenegro. 19--. 